BMC

Evolutionary Biology

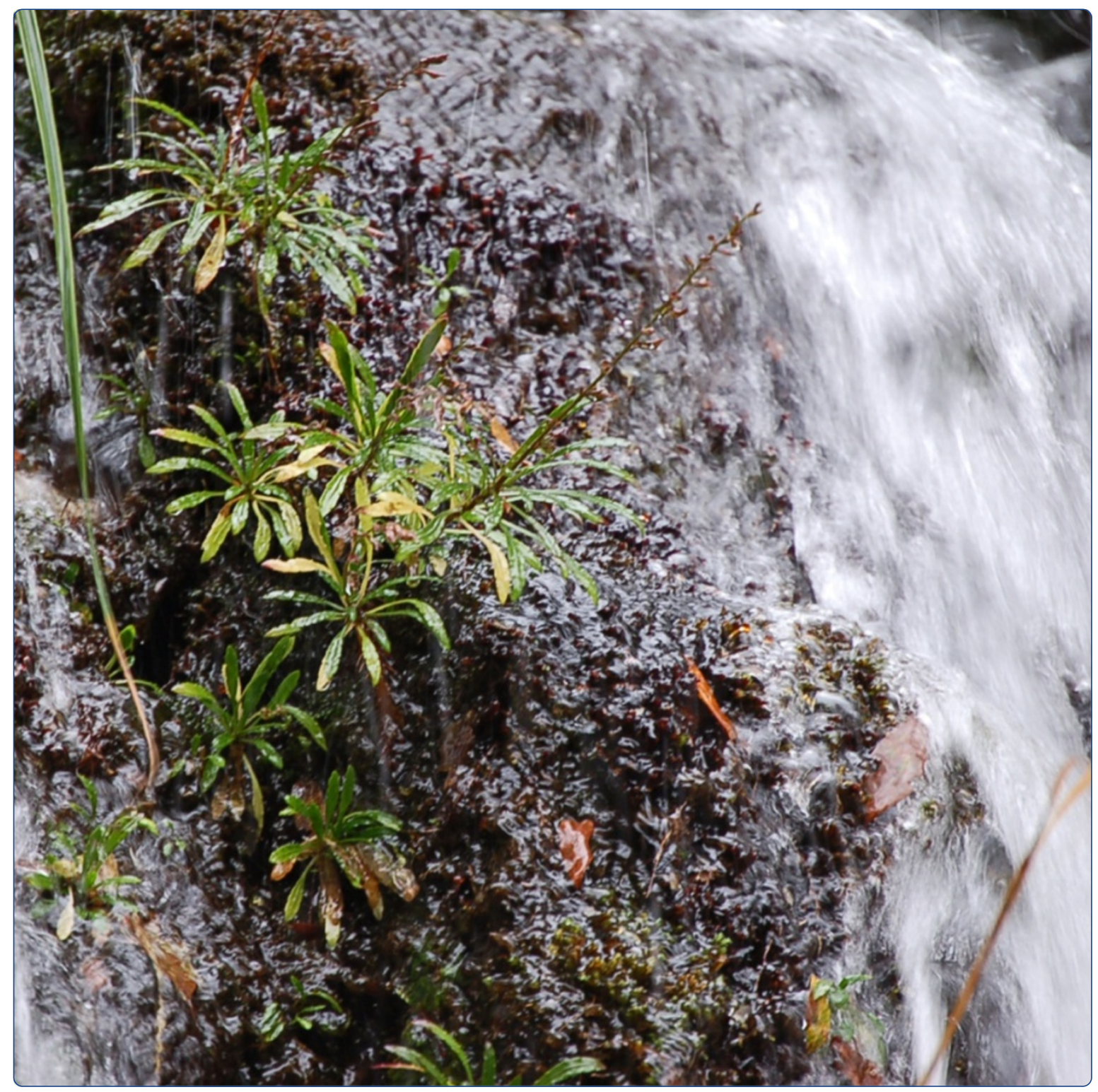

Demographic histories of adaptively diverged riparian and non-riparian species of Ainsliaea (Asteraceae) inferred from coalescent analyses using multiple nuclear loci

Mitsui and Setoguchi 


\title{
Demographic histories of adaptively diverged riparian and non-riparian species of Ainsliaea (Asteraceae) inferred from coalescent analyses using multiple nuclear loci
}

Yuki Mitsui ${ }^{i^{*}}$ and Hiroaki Setoguchi ${ }^{2}$

\begin{abstract}
Background: Understanding demographic histories, such as divergence time, patterns of gene flow, and population size changes, in ecologically diverging lineages provide implications for the process and maintenance of population differentiation by ecological adaptation. This study addressed the demographic histories in two independently derived lineages of flood-resistant riparian plants and their non-riparian relatives [Ainsliaea linearis (riparian) and A. apiculata (non-riparian); A. oblonga (riparian) and A. macroclinidioides (non-riparian); Asteraceae] using an isolation-with-migration (IM) model based on variation at 10 nuclear DNA loci.

Results: The highest posterior probabilities of the divergence time parameters were estimated to be ca. 25,000 years ago for A. linearis and A. apiculata and ca. 9000 years ago for A. oblonga and A. macroclinidioides, although the confidence intervals of the parameters had broad ranges. The likelihood ratio tests detected evidence of historical gene flow between both riparian/non-riparian species pairs. The riparian populations showed lower levels of genetic diversity and a significant reduction in effective population sizes compared to the non-riparian populations and their ancestral populations.

Conclusions: This study showed the recent origins of flood-resistant riparian plants, which are remarkable examples of plant ecological adaptation. The recent divergence and genetic signatures of historical gene flow among riparian/non-riparian species implied that they underwent morphological and ecological differentiation within short evolutionary timescales and have maintained their species boundaries in the face of gene flow. Comparative analyses of adaptive divergence in two sets of riparian/non-riparian lineages suggested that strong natural selection by flooding had frequently reduced the genetic diversity and size of riparian populations through genetic drift, possibly leading to fixation of adaptive traits in riparian populations. The two sets of riparian/non-riparian lineages showed contrasting patterns of gene flow and genetic differentiation, implying that each lineage showed different degrees of reproductive isolation and that they had experienced unique evolutionary and demographic histories in the process of adaptive divergence.
\end{abstract}

Keywords: Adaptive divergence, Divergence time, Effective population size, Gene flow, Isolation-with-migration model, Riparian plants

\footnotetext{
* Correspondence: y3mitsui@nodai.ac.jp

${ }^{1}$ Faculty of Agriculture, Tokyo University of Agriculture, Funako 1737, Atsugi,

Kanagawa 243-0034, Japan

Full list of author information is available at the end of the article
} 


\section{Background}

Adaptation to diverse ecological habitats is a major force driving population differentiation, leading to the evolution of reproductive isolation, and ultimately speciation (Schluter, [1,2]; Coyne \& Orr, [3]; Rundle \& Nosil, [4]; Sobel et al. [5]). Theoretical studies suggest that populations in differential ecological habitats can develop reproductive isolation through divergent natural selection in a few thousand generations (Gavrilets \& Vose, [6]) or even in dozens to hundreds of generations (Hendry et al. [7]). Recently, progress in molecular and population genetic techniques has allowed us to estimate the evolutionary and demographic histories of recently diverged populations or species reliably. For example, model-based simulation analysis, such as the isolationwith-migration (IM) model (Hey \& Nielsen, [8]; Hey, [9]), can simultaneously estimate the divergence time, bidirectional gene flow since the initial split, and fluctuations in effective population sizes among recently diverged lineages based on the nucleotide variation at multiple loci. Estimates of these demographic parameters in ecologically divergent lineages provide important insights into evolutionary histories, population dynamics, and the maintenance of adaptive divergence.

The flood-resistant riparian plants referred to as rheophytes (van Steenis [10]) are remarkable examples of plant ecological adaptation. They are riparian specialists that inhabit riverbank habitats, where individuals are subjected to frequent submergence during intermittent floods after heavy rains. There are several advantages to using flood-resistant riparian plants to investigate the mechanisms of adaptive ecological divergence. First, the major selective force (flooding) and the resultant adaptive trait evolution (narrow, thick leaves) are explicit. To resist a strong flow of water, these plants typically evolve a narrow, thick leaf (Usukura et al. [11]; Imaichi \& Kato, [12]; Kato, [13]; Tsukaya, [14]; Setoguchi \& Kajimaru, [15]; Nomura et al. [16]), increasing mechanical toughness of the leaves (van Steenis, [10]). Second, floodresistant riparian plants and their close non-riparian relatives with distinct phenotypes (round, broad leaves) are often found in parapatry across riverbank-forest floor transitions (van Steenis, [10]; Kato, [13]; Mitsui et al. [17]). The non-riparian relatives inhabit adjacent forest floor environments where flooding never reaches, providing opportunities to investigate divergence via divergent natural selection resulting from differential ecological habitats. Non-riparian relatives usually have much wider ranges than the riparian species, implying that most riparian lineages are derived from inland progenitors after pioneering in flood habitats in each locality (Kato, [13]). Third, most of these riparian taxa are considered to have evolved convergently in each region via local adaptation because they occupy separate taxonomic groups in angiosperms, as well as pteridophytes, which are found worldwide. Approximately 1,000 riparian vascular plant species have been reported (van Steenis [18]), and most (75\%) are considered to be locally endemic with quite narrow ranges (Kato, [13]). Therefore, comparative analysis of adaptive divergence among independently evolved riparian lineages is possible.

This study investigated the evolutionary and demographic history of the adaptively diverged plants in Ainsliaea (Asteraceae); two independent lineages of flood-resistant perennial species, Ainsliaea linearis Makino and A. oblonga Koidz., and their closely related species distributed in the Japanese archipelago (Figure 1). Ainsliaea linearis is endemic to Yakushima Island, in the southern part of the Japanese archipelago (Figure 2). It is a riparian species that is strictly confined to rocky surfaces or crevices along riverbanks, where individuals are often subjected to flash floods after rains. A. linearis has developed narrow, streamlined leaves (Figure 1a). Ainsliaea apiculata Sch. Bip., the sister species of A. linearis (Mitsui \& Setoguchi, [19]), is distributed across the Japanese archipelago, and Yakushima Island is the southernmost part of its range (Figure 2). A. apiculata has ovate or rounded leaves with shallow lobes and inhabits the floor or margins of deciduous or conifer forests (Figure 1d). Its range largely overlaps that of $A$. linearis on Yakushima Island, where the two species frequently grow in parapatry across riverbank-forestry transitions (Watanabe et al. [20]). A recent study using microsatellite DNA markers indicated that parapatric populations of $A$. linearis (synonym: A. faurieana Beauv.) and A. apiculata are isolated reproductively, mainly by divergent natural selection arising from their contrasting riparian and inland habitats, despite ongoing hybridization (Mitsui et al. [17]). Despite their distinct morphology and ecology, little genetic differentiation in some nuclear and chloroplast DNA regions has been detected within this monophyletic group (Mitsui et al. [21]). This implies that the adaptive divergence occurred over a relatively short evolutionary timescale.

Another riparian species, Ainsliaea oblonga, is endemic to Okinawa Island, part of the Ryukyu-Taiwan island chain, which is located between southeast China and mainland Japan (Figure 2). A. oblonga, like A. linearis, grows in flooded habitats. The leaves of $A$. oblonga are long and elliptical, and the base is cuneate, showing adaptive characteristics in flooded habitats (Koyama, [22]; Figure $1 \mathrm{~b})$. The closely related sister species $A$. macroclinidioides Hayata is widely distributed across the RyukyuTaiwan island chain (Mitsui \& Setoguchi, [19]). It has ovate or rounded leaves with shallow lobes and inhabits the floor or margins of laurel forests (Figure 1e). The two species occur together in northern Okinawa Island. A. oblonga grows along riverbanks in gorges that are flooded regularly, while $A$. macroclinidioides grows on 

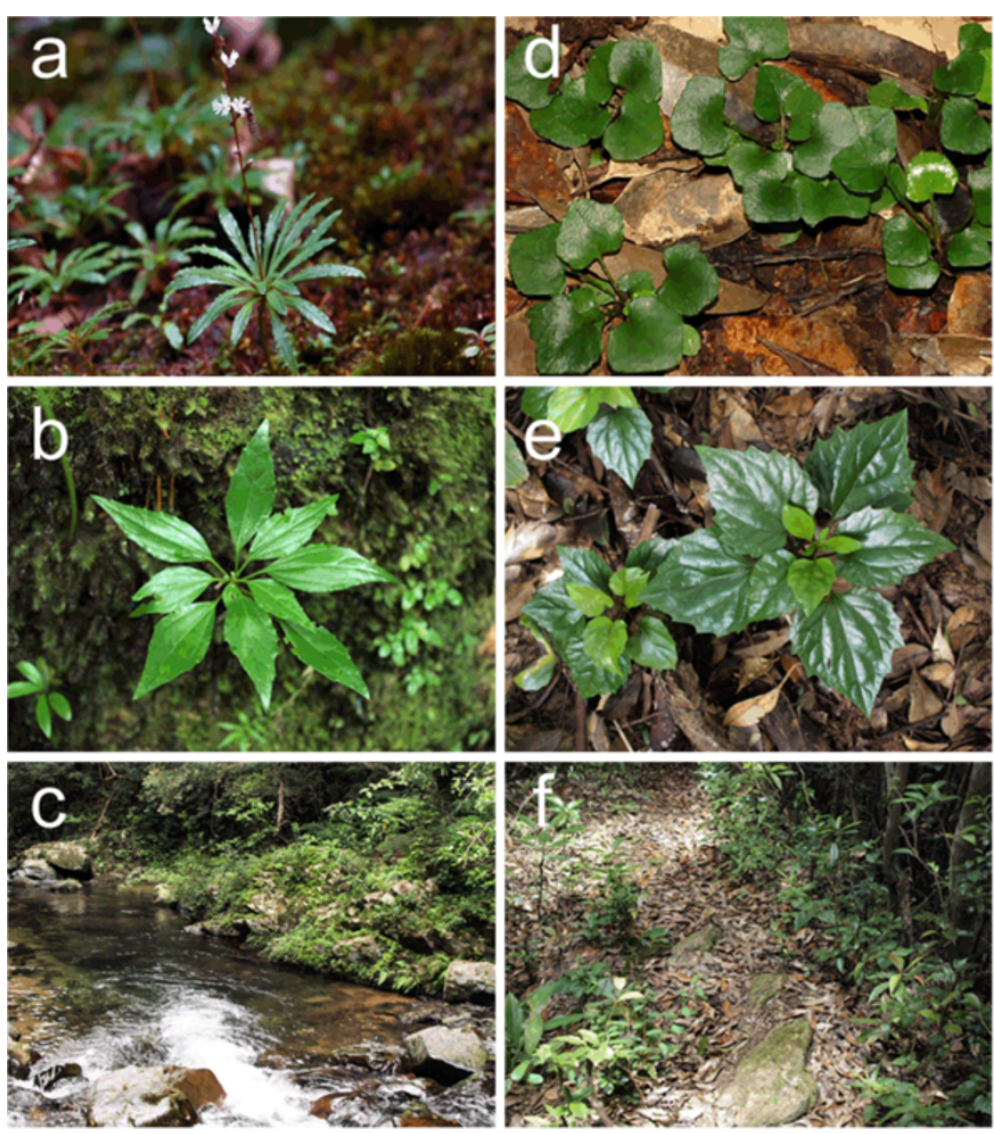

Figure 1 Photos of the riparian species (a) Ainsliaea linearis, (b) A. oblonga and (c) their habitats, and photos of the inland species (d) A. apiculata, (e) A. macroclinidioides and (f) their habitats.

upper slopes and ridges. Although the two species are often distributed in contact (up to tens to hundreds of meters), they show clear segregation in flooded and forest floor habitats. In common garden experiments, the leaf shapes of the two species were stable, suggesting that the morphological characteristics are fixed genetically. In addition, viable, fertile hybrids with an intermediate leaf shape can be produced with artificial crossing (M. Mitsui, unpublished). In natural populations, however, intermediate phenotypes have not been seen, suggesting that the divergence of $A$. oblonga and A. macroclinidioides is likely maintained by ecological factors, such as habitat segregation that could lead to pre- or post-mating isolation.

We investigated the divergence time, significance and directions of gene flow, and effective population size differences among riparian (specialist, localized) and nonriparian (generalist, widespread) species in Ainsliaea (Asteraceae) using the IM model based on the multilocus datasets of nuclear gene sequences. The specific hypotheses addressed are the following. First, the initial events splitting the riparian and non-riparian species might be recent, despite their distinct morphological and ecological differences. Second, with adaptive divergence between the riparian and non-riparian populations, they could have exchanged genes since the initial split. The patterns of gene flow (bidirectional, unidirectional, or no gene flow) might have implications for population dynamics, the relative strength of reproductive isolation, and selective pressures between the ecologically divergent riparian/non-riparian lineages. Third, the riparian specialists could have less genetic variation and smaller effective population sizes than the non-riparian populations owing to genetic drift. Comparative analyses of the two riparian species with different origins might show common or different patterns of divergence, providing implications for the process and maintenance of adaptive divergence to highly disturbed flooded habitats in this group of taxa.

\section{Results}

Patterns of polymorphism and genetic divergence in riparian and non-riparian species

We sequenced 10 nuclear loci with a total length of 4502 bp from 70 individuals representing 6 populations of A. linearis, 12 of A. apiculata, 4 of A. oblonga, and 10 populations of $A$. macroclinidioides. The length of the 


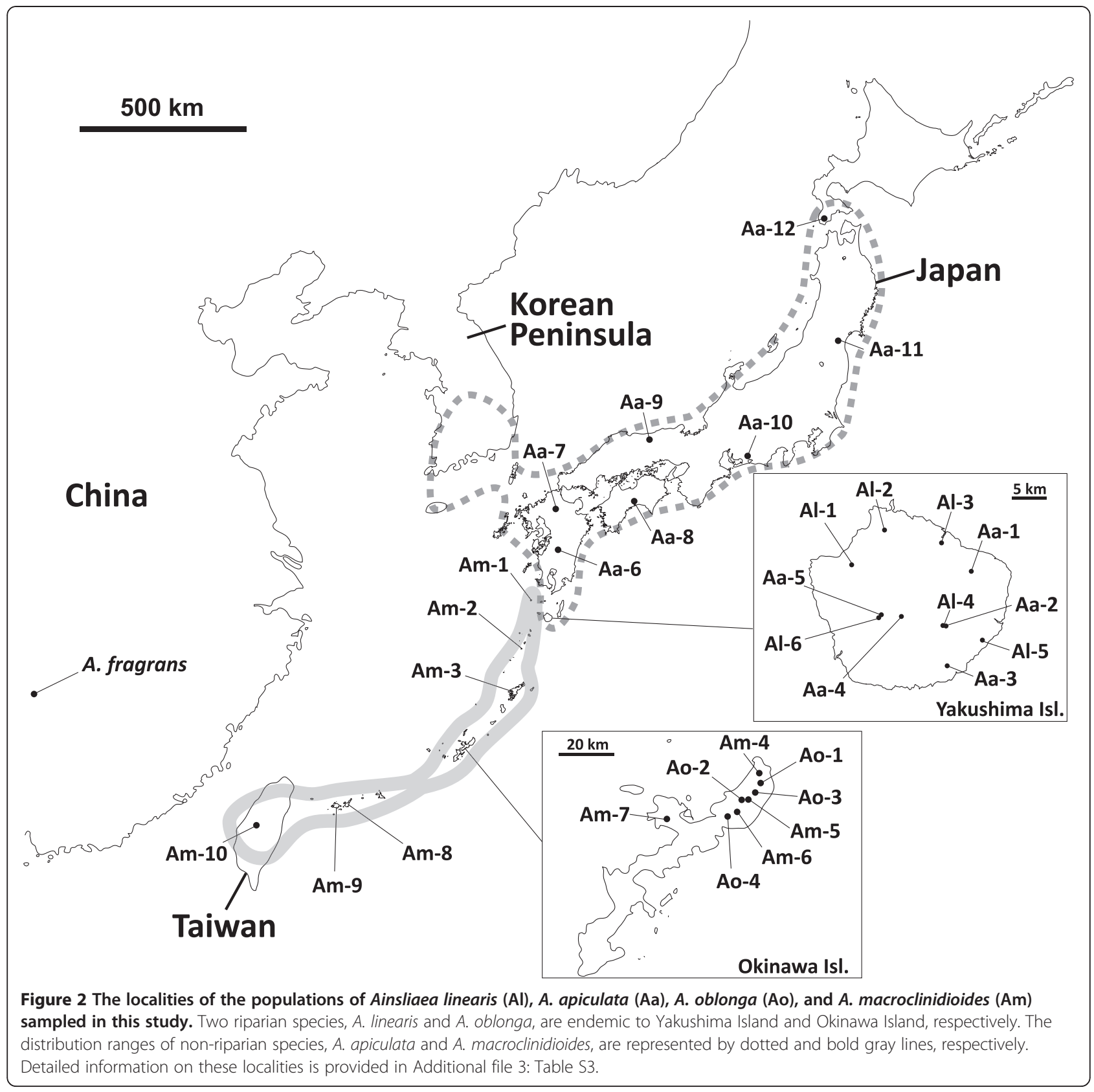

aligned sequences for each locus ranged from 255 to 707 bp (Table 1). We found five insertion-deletion (indel) polymorphisms across all loci, but we did not include indels in the subsequent analyses. All sequences with different haplotypes (Additional file 1: Table S1) were deposited in the DNA Data Bank of Japan (DDBJ), with accession numbers AB601211-AB601418.

The sequence polymorphisms and divergence between each monophyletic pair of riparian and non-riparian species (i.e., between $A$. linearis and A. apiculata and between $A$. oblonga and $A$. macroclinidioides) are compared in Table 1. For A. macroclinidioides, the southern populations were excluded from the analyses because they clustered as distinct lineages in the phylogenetic analyses (see the results below). The genetic divergence between riparian and inland species was fairly small, and most of the polymorphisms were shared between them. The fixed nucleotide differences between $A$. linearis and A. apiculata averaged 0.8 per locus, while no fixed difference was observed between $A$. oblonga and $A$. macroclinidioides. We found that the riparian species tended to have fewer polymorphic sites and recombination events, and lower nucleotide diversities than the inland sister species. 
Table 1 Summary of nucleotide polymorphisms and genetic divergence of 10 loci for each monophyletic riparian and non-riparian species

\begin{tabular}{|c|c|c|c|c|c|c|c|c|c|c|c|c|c|c|}
\hline \multirow[b]{2}{*}{ Locus } & \multirow[b]{2}{*}{$\begin{array}{l}\text { Aligned size } \\
\text { (bp) }\end{array}$} & \multirow[b]{2}{*}{$\begin{array}{c}\text { Largest } \\
\text { non-recombining } \\
\text { block }\end{array}$} & \multicolumn{5}{|c|}{ A. linearis (riparian) } & \multicolumn{5}{|c|}{ A. apiculata (non-riparian) } & \multicolumn{2}{|c|}{ Divergence } \\
\hline & & & No. of seqs. & $S$ & $\pi$ & $\theta$ & $R m$ & No. of seqs. & $s$ & $\pi$ & $\theta$ & $R m$ & $S_{\mathrm{f}}$ & $D_{\mathrm{XY}}$ \\
\hline GA20x1 & 707 & 642 & 24 & 3 & 0.0015 & 0.0011 & 0 & 48 & 4 & 0.0008 & 0.0011 & 0 & 0 & 0.0027 \\
\hline $\mathrm{CHS}$ & 358 & 358 & 24 & 1 & 0.0011 & 0.0008 & 0 & 48 & 1 & 0.0011 & 0.0008 & 0 & 0 & 0.0011 \\
\hline GTF & 382 & 240 & 24 & 0 & 0.0000 & 0.0000 & 0 & 48 & 5 & 0.0043 & 0.0000 & 1 & 1 & 0.0054 \\
\hline CPPS1 & 501 & 501 & 24 & 1 & 0.0006 & 0.0005 & 0 & 48 & 1 & 0.0000 & 0.0005 & 0 & 0 & 0.0016 \\
\hline A25 & 280 & 236 & 24 & 3 & 0.0033 & 0.0029 & 0 & 48 & 4 & 0.0030 & 0.0029 & 0 & 0 & 0.0038 \\
\hline A27 & 685 & 638 & 24 & 0 & 0.0000 & 0.0000 & 0 & 48 & 7 & 0.0022 & 0.0000 & 1 & 3 & 0.0082 \\
\hline B12 & 255 & 255 & 24 & 0 & 0.0000 & 0.0000 & 0 & 48 & 2 & 0.0003 & 0.0000 & 0 & 0 & 0.0005 \\
\hline D10 & 361 & 361 & 24 & 4 & 0.0013 & 0.0030 & 0 & 48 & 4 & 0.0041 & 0.0030 & 0 & 0 & 0.0030 \\
\hline$\overline{D 13}$ & 504 & 504 & 24 & 3 & 0.0017 & 0.0016 & 0 & 48 & 1 & 0.0011 & 0.0016 & 0 & 4 & 0.0105 \\
\hline D22 & 469 & 235 & 24 & 0 & 0.0000 & 0.0000 & 0 & 48 & 3 & 0.0022 & 0.0000 & 2 & 0 & 0.0033 \\
\hline \multirow[t]{2}{*}{ Mean } & 450 & 397 & 24 & 1.5 & 0.0009 & 0.0010 & 0 & 48 & 3.2 & 0.0019 & 0.0010 & 0.4 & 0.8 & 0.0040 \\
\hline & & & \multicolumn{5}{|c|}{ A. oblonga (riparian) } & \multicolumn{5}{|c|}{ A. macroclinidioides (non-riparian) } & \multicolumn{2}{|c|}{ Divergenc } \\
\hline Locus & $\begin{array}{l}\text { Aligned size } \\
\text { (bp) }\end{array}$ & $\begin{array}{c}\text { Largest } \\
\text { non-recombining } \\
\text { block }\end{array}$ & No. of seqs. & $s$ & $\pi$ & $\theta$ & $R m$ & No. of seqs. & $s$ & $\pi$ & $\theta$ & $R m$ & $S_{\mathrm{f}}$ & $D_{\mathrm{XY}}$ \\
\hline GA20x1 & 707 & 505 & 24 & 4 & 0.0007 & 0.0015 & 0 & 28 & 8 & 0.0033 & 0.0029 & 1 & 0 & 0.0022 \\
\hline $\mathrm{CHS}$ & 358 & 358 & 24 & 1 & 0.0015 & 0.0008 & 0 & 28 & 3 & 0.0017 & 0.0022 & 0 & 0 & 0.0018 \\
\hline GTF & 382 & 132 & 24 & 1 & 0.0009 & 0.0007 & 0 & 28 & 4 & 0.0043 & 0.0027 & 1 & 0 & 0.0038 \\
\hline CPPS1 & 501 & 501 & 24 & 1 & 0.0006 & 0.0005 & 0 & 28 & 1 & 0.0001 & 0.0005 & 0 & 0 & 0.0004 \\
\hline A25 & 280 & 222 & 24 & 2 & 0.0015 & 0.0018 & 0 & 28 & 4 & 0.0050 & 0.0035 & 1 & 0 & 0.0040 \\
\hline A27 & 685 & 434 & 24 & 10 & 0.0068 & 0.0039 & 3 & 28 & 11 & 0.0076 & 0.0041 & 3 & 0 & 0.0073 \\
\hline $\mathrm{B} 12$ & 255 & 255 & 24 & 1 & 0.0017 & 0.0011 & 0 & 28 & 1 & 0.0017 & 0.0010 & 0 & 0 & 0.0016 \\
\hline D10 & 361 & 195 & 24 & 5 & 0.0042 & 0.0037 & 1 & 28 & 4 & 0.0032 & 0.0029 & 2 & 0 & 0.0043 \\
\hline D13 & 504 & 421 & 24 & 5 & 0.0030 & 0.0026 & 1 & 28 & 6 & 0.0048 & 0.0030 & 0 & 0 & 0.0047 \\
\hline D22 & 469 & 302 & 24 & 6 & 0.0031 & 0.0034 & 0 & 28 & 6 & 0.0042 & 0.0033 & 2 & 0 & 0.0053 \\
\hline Mean & 450 & 333 & 24 & 3.6 & 0.0024 & 0.0020 & 0.5 & 28 & 4.8 & 0.0036 & 0.0026 & 1.0 & 0 & 0.0035 \\
\hline
\end{tabular}

$S$, number of segregating (polymorphic) sites.

$\pi$, average number of pairwise nucleotide differences per site.

$\theta$, Watterson's estimator of $\theta$ per base pair.

$R m$, estimate of the minimum number of recombination events.

$S_{f}$, number of segregating sites that are fixed between the two speices.

$D_{\mathrm{XY}}$, average proportion of nucleotide differences between species.

None of the loci showed a consistently significant deviation from neutral expectations for Tajima's $D$ or Fu and Li's $D^{*}$ and $F^{*}$ statistics, except the A27 locus for A. oblonga and A. macroclinidioides (Additional file 2: Table S2). For this locus, A. oblonga and A. macroclinidioides showed significant deviation from neutral expectations in all three tests. Since Tajima's $D$-statistic is sensitive to population structure and demography (Tajima, [23]), we performed a multi-locus Hudson, Kreitman \& Aguad (HKA) test, which is robust to population structure and demography. When using one sequence of $A$. fragrans, which occurs in southeast China, as an outgroup, we did not detect a significant departure from the equilibrium model for any of the comparisons between each species and the outgroup $\left(\chi^{2}=3.09, P>0.66\right.$ for A. linearis; $\chi^{2}=2.04, P>0.63$ for $A$. apiculata; $\chi^{2}=2.22, P>0.64$ for A. oblonga; and $\chi^{2}=1.53, P>0.53$ for A. macroclinidioides). None of the 10 loci showed evidence of being under selection using all of the statistics for the species examined, and we used all loci for the subsequent analyses. Note that inclusion or exclusion of the A27 locus in the analyses did not significantly change the results.

\section{Phylogenetic relationships and population structure}

The phylogenetic network reconstructed using NeighborNet analysis showed that the populations of the riparian species A. linearis formed a cluster (Figure 3A). Conversely, the populations of the other riparian species, $A$. oblonga, were not separated genetically from the non-riparian relative, A. macroclinidioides. The genetic 
A

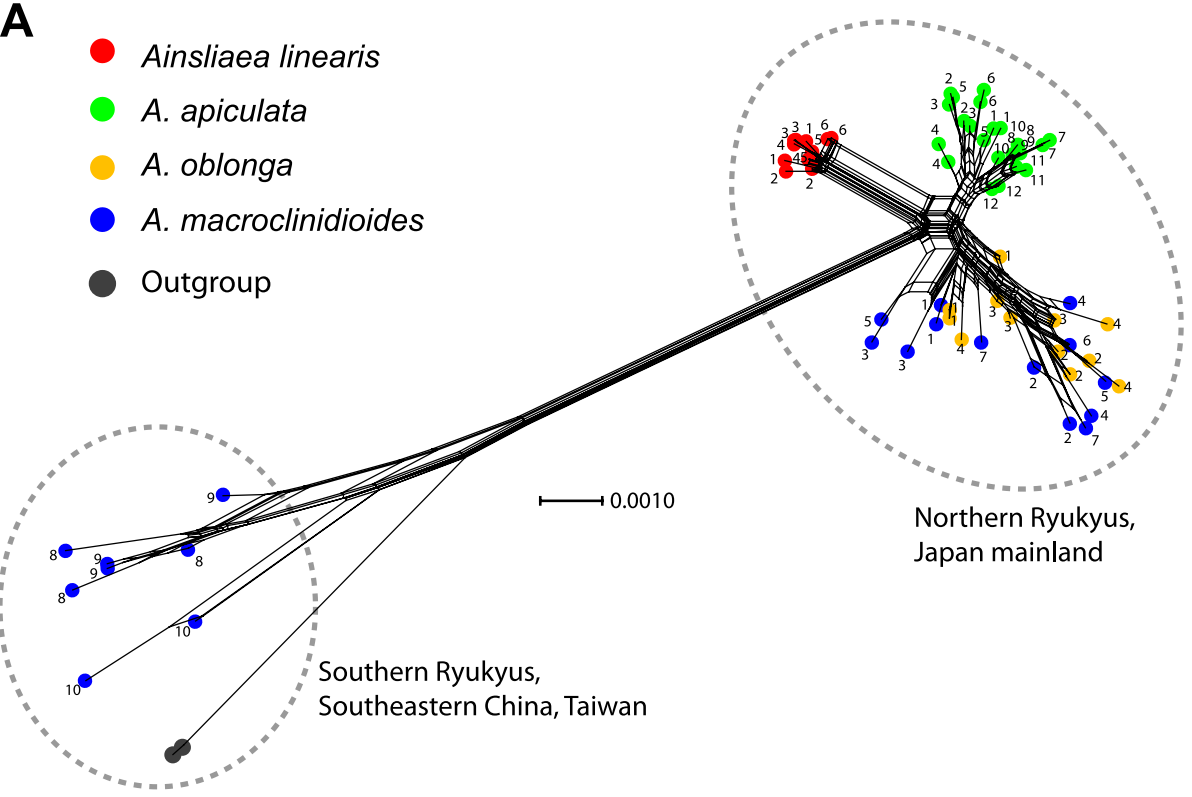

B

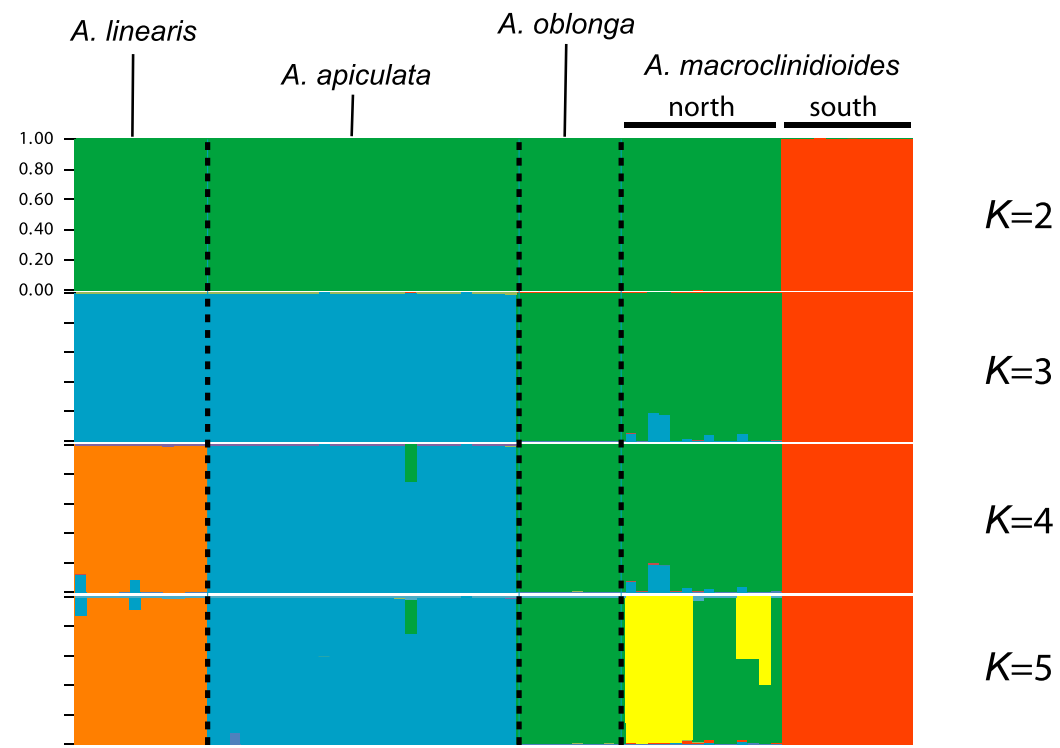

Figure 3 (A) Phylogenetic network of the four species and outgroup of Ainsliaea reconstructed with the NeighborNet method.

The network is based on the combined sequences of 10 nuclear gene loci (total length 4502 bp) from 72 individuals, including two outgroup individuals. Each individual is numbered according to its locality. (B) Assignments of individuals to clusters $(K=2-5)$ for the four species inferred by STRUCTURE. The clustering pattern was highly consistent across 20 independent runs for each cluster, and one of the results is shown.

admixture in A. oblonga and A. macroclinidioides was also indicated in the STRUCTURE analysis (Figure 3B). The most likely number of clusters was four when the $\Delta K$ statistic of Evanno et al. [24] was applied $(\Delta K=239.8)$. When $K=4$, A. linearis and $A$. apiculata comprised different clusters, while $A$. oblonga and $A$. macroclinidioides were not separated from each other. The genetic admixture in the STRUCTURE analysis could reflect recent introgression between the two species (Duchesne \& Turgeon, [25]).
By contrast, the phylogenetic and STRUCTURE analyses showed that the A. macroclinidioides populations exhibited distinct genetic structuring with regard to the northern (populations Am1-7) and southern (populations Am8-10) regions of the Ryukyu-Taiwan island chain, suggesting that $A$. macroclinidioides is a nonmonophyletic group. The southern populations showed close relationships with Chinese outgroup species. There was no evidence of within-species geographical structuring for the four species, with the exception of 
A. macroclinidioides. Therefore, the southern populations of $A$. macroclinidioides were excluded from the riparian/non-riparian comparisons.

\section{Estimating demographic parameters}

The maximum-likelihood estimates (MLEs) and 90\% highest posterior density (HPD) of the population genetic parameters estimated by IM are shown in Table 2. The parameter estimates were scaled using the geometric mean of the per locus mutation rate to make the parameters more easily interpretable. The analyses were conducted separately for each monophyletic pair of riparian and non-riparian species.

In the divergence parameter estimation the three independent runs consistently showed a sharp peak in each dataset, however, the marginal posterior probability distribution of the parameter did not drop to zero when sufficiently high values were reached. The MLEs of the divergence parameters were $c a$. 25,000 years ago (90\% HPD 9074-3,131,867 years ago) for $A$. linearis and A. apiculata and ca. 9000 years ago (90\% HPD 1815-3,624,008 years ago) for $A$. oblonga and $A$. macroclinidioides (Figure 4). The estimated wide confidence intervals were likely due to small data set that may not be enough to achieve convergence.

The strict isolation model in which no gene flow occurred during the divergence of the two sets of riparian and inland species was rejected by likelihood ratio tests for both pairs (Table 3; the likelihoods of the models with $m_{1}=0 m_{2}=0$ were significantly low than that of the full model). The gene flow between riparian $A$. linearis and non-riparian $A$. apiculata was estimated to be unidirectional; the gene flow from $A$. apiculata to A. linearis was significantly greater than zero $\left(\mathrm{m}_{1}=0.007,90 \% \mathrm{HPD}\right.$ 0.000-0.023), while there was no evidence of gene flow in the opposite direction $\left(\mathrm{m}_{2}=0.001,90 \%\right.$ HPD $0.000-0.008$; Table 2). The population migration rates was 0.127 $\left(2 \mathrm{~N}_{1} \mathrm{~m}_{1}\right)$ from $A$. apiculata to $A$. linearis and 0.051 $\left(2 \mathrm{~N}_{2} \mathrm{~m}_{2}\right)$ in the opposite direction.

More gene flow was detected between riparian $A$. oblonga and non-riparian $A$. macroclinidioides, although the probability distributions did not show sharp peaks (Figure 4). Both directions of gene flow were significantly greater than zero (Table 3 ). The gene flow from non-riparian $A$. macroclinidioides to riparian $A$. oblonga was also higher $\left(\mathrm{m}_{1}=0.057,90 \% \mathrm{HPD} 0.009-0.168\right)$ than in the opposite direction $\left(\mathrm{m}_{2}=0.023,90 \% \mathrm{HPD}\right.$ 0.005-0.063; Table 2). However, the population migration rates showed the opposite results; from $A$. macroclinidioides to $A$. oblonga $\left(2 \mathrm{~N}_{1} \mathrm{~m}_{1}\right)=0.526$ and that in the opposite direction $\left(2 \mathrm{~N}_{2} \mathrm{~m}_{2}\right)$ was 2.499 , suggesting that the amount and direction of gene flow between the two sets of riparian/non-riparian lineages differed in each group.

We found that the effective populations of riparian species were significantly smaller than those of nonriparian species (Tables 2 and 3, Figure 4). The estimated effective population size of $A$. linearis was 8,643 (90\% HPD 4010-21,473), nearly one-third that of $A$. apiculata (ca. 23,800; 90\% HPD 12,483-45,014). The population size difference between $A$. oblonga and A. macroclinidioides was more remarkable. The riparian $A$. oblonga had the smallest effective population $(4,579 ; 90 \%$ HPD

Table 2 Maximum-likelihood estimates (MLEs) and the $90 \%$ highest posterior density (HPD) intervals of model parameters from IMa analyses

\begin{tabular}{|c|c|c|c|c|c|c|c|c|c|c|c|c|c|c|}
\hline & $\theta_{1}$ & $\theta_{2}$ & $\theta_{\mathrm{A}}$ & $m_{1}$ & $m_{2}$ & $t$ & $\mathrm{~N}_{1}$ & $\mathrm{~N}_{2}$ & $\mathrm{~N}_{\mathrm{A}}$ & $\mathrm{m}_{1}$ & $\mathrm{~m}_{2}$ & $2 \mathrm{~N}_{1} \mathrm{~m}_{1}$ & $2 \mathrm{~N}_{2} \mathrm{~m}_{2}$ & $\mathbf{T}$ (year) \\
\hline \multicolumn{15}{|c|}{ (1) A. linearis vs. (2) A. apiculata } \\
\hline MLE & 0.095 & 0.263 & 0.718 & 2.665 & 0.388 & 0.065 & 8643 & 23831 & 65189 & 0.007 & 0.001 & 0.127 & 0.051 & 24782 \\
\hline HPD90LO & 0.040 & 0.132 & 0.004 & 0.655 & 0.005 & 0.018 & 4010 & 12483 & 9709 & 0.000 & 0.000 & 0.013 & 0.000 & 9074 \\
\hline $\mathrm{HPD} 90 \mathrm{Hi}$ & 0.207 & 0.454 & 7.171 & 6.538 & 1.802 & 8.628 & 21473 & 45014 & 704721 & 0.023 & 0.008 & 0.677 & 0.409 & 3131867 \\
\hline \multicolumn{15}{|c|}{ (1) A. oblonga vs. (2) A. macroclinidioides (north) } \\
\hline MLE & 0.053 & 0.492 & 0.772 & 19.827 & 10.165 & 0.025 & 4579 & 44819 & 70084 & 0.057 & 0.023 & 0.526 & 2.499 & 9074 \\
\hline HPD90LO & 0.022 & 0.223 & 0.006 & 4.777 & 2.925 & 0.005 & 1902 & 20152 & 501 & 0.009 & 0.005 & 0.053 & 0.326 & 1815 \\
\hline $\mathrm{HPD} 90 \mathrm{Hi}$ & 0.170 & 0.912 & 9.641 & 48.573 & 23.715 & 9.985 & 15007 & 82918 & 873072 & 0.168 & 0.063 & 4.118 & 10.810 & 3624008 \\
\hline \multicolumn{15}{|c|}{ (1) North vs. (2) South } \\
\hline MLE & 0.436 & 0.585 & 0.158 & 0.005 & 0.208 & 1.605 & 60536 & 81181 & 21950 & 0.000 & 0.000 & 0.001 & 0.061 & 890679 \\
\hline HPD90LO & 0.264 & 0.354 & 0.013 & 0.005 & 0.035 & 0.545 & 36578 & 49127 & 1742 & 0.000 & 0.000 & 0.001 & 0.006 & 302442 \\
\hline $\mathrm{HPD} 90 \mathrm{Hi}$ & 0.668 & 0.927 & 12.359 & 0.215 & 0.488 & 26.835 & 92622 & 128566 & 1714557 & 0.001 & 0.001 & 0.072 & 0.226 & 14891815 \\
\hline
\end{tabular}

$\mathrm{N}_{1}, \mathrm{~N}_{2}, \mathrm{~N}_{\mathrm{A}}$ : effective population sizes of population 1,2 and ancestral. $\theta=4 \mathrm{Nu}$.

$m_{1}$ : the rate of gene flow from population 2 to population 1 per gene per generation. $m_{1}=m_{1} / u$.

$m_{2}$ : the rate of gene flow from population 1 to population 2 per gene per generation. $m_{2}=m_{2} / u$.

$2 \mathrm{~N}_{1} \mathrm{~m}_{1}$ : the effective rate of gene flow from population 2 to population 1 per generation.

$2 \mathrm{~N}_{2} \mathrm{~m}_{2}$ : the effective rate of gene flow from population 1 to population 2 per generation.

Each value is the average of three independent runs of the simulations. Demographic quantities, $N_{1}, N_{2}, N_{A}, m_{1}, m_{2}$, and T, were converted based on a mutation rate $(u)$ of $7.49 \times 10^{-9}$ substitutions/site/year. 

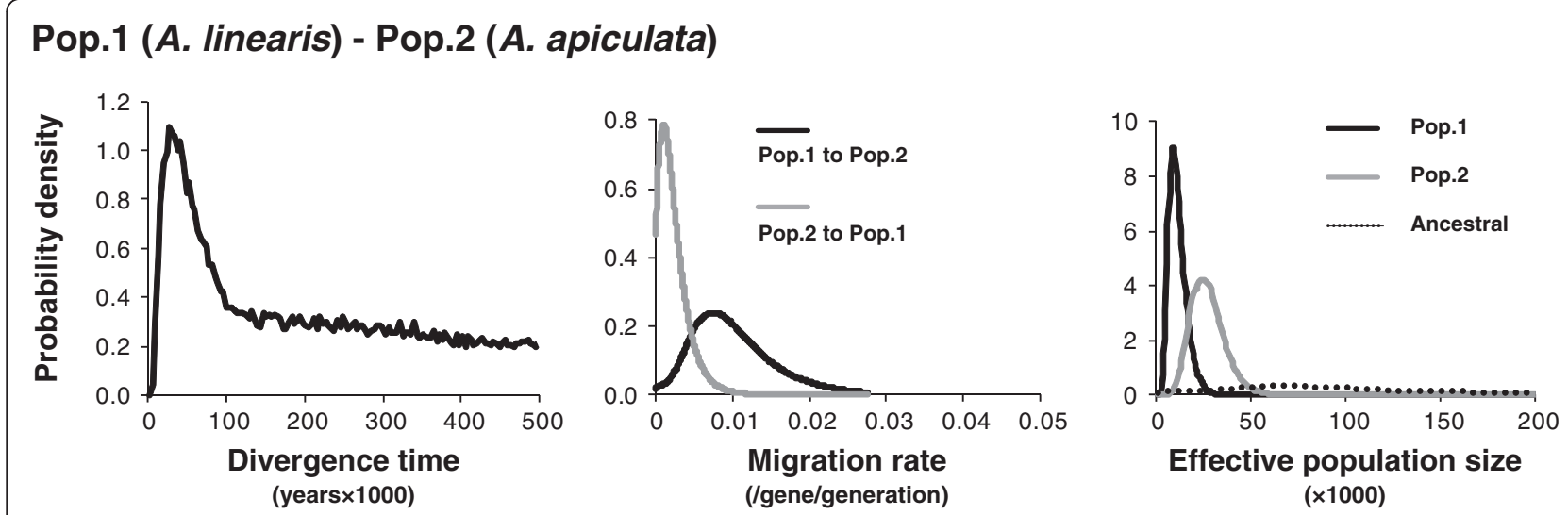

\section{Pop.1 (A. oblonga) - Pop.2 (A. macroclinidioides)}
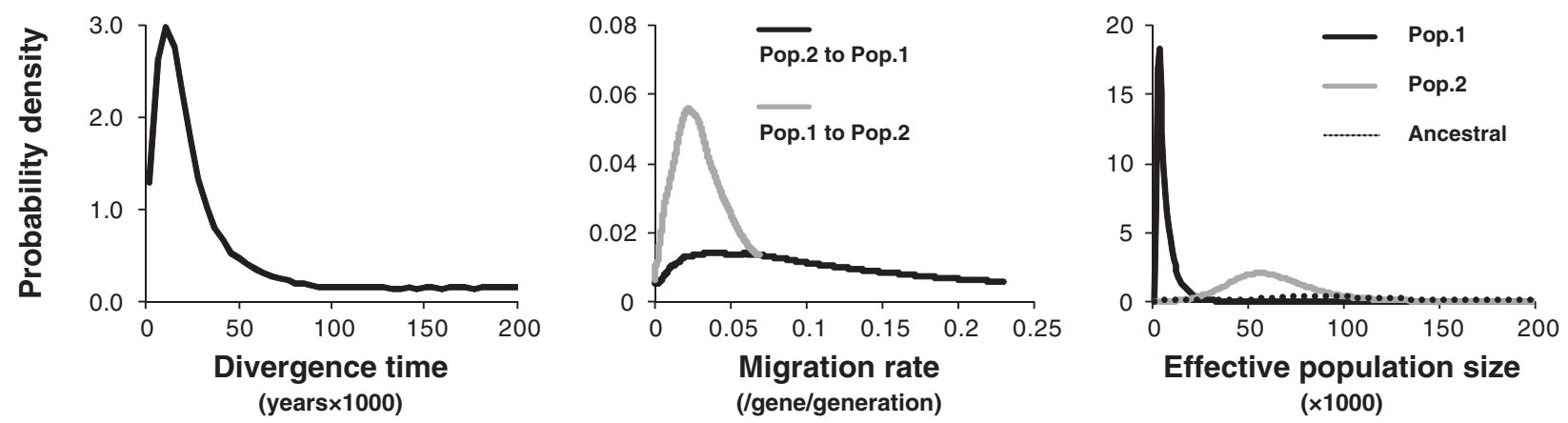

Figure 4 Marginal distribution of the posterior probability of divergence time (years $\times 1000$ ), migration rates per gene per generation, and effective population sizes $(\times 1000)$ estimated by IMa analyses conducted for each pair of riparian and non-riparian species.

1902-15,007), nearly one-tenth that of the northern lineage of $A$. macroclinidioides (44,819; 90\% HPD 20,152$82,918)$. The effective sizes of the ancestral populations tended to be larger than the descendent populations, although the posterior probabilities had wide, flat distributions. This significant reduction in the population size of riparian species is consistent with the relatively low genetic diversity compared with the non-riparian species.

\section{Discussion}

\section{Origins of the two flood-resistant species of Ainsliaea}

According to our estimation of demographic parameters using the IM model, the initial splits of the floodresistant riparian plants in Ainsliaea might have occurred over short evolutionary timescales. Given the wide confidence intervals, however, there is uncertainty in the divergence time estimates. Such wide intervals were likely due to relatively small data set. The previous studies showed that the divergence time parameter tended not to reach to convergence for the recently diverged populations or taxa (Hey et al. [26]; Ikeda et al. [27]). The riparian and non-riparian relatives showed fairly low genetic differentiation that is consistent with the previous study using some nuclear and chloroplast DNA sequences (Mitsui et al. [21]). Based on the fact that the riparian/non-riparian species can hybridize and produce fertile progenies, our results support recent origins and rapid phenotypic evolution via adaptation to flooded habitats in this group of taxa. These findings are consistent with postulates that ecological differences can drive the evolution of phenotypes and partial reproductive barriers within short evolutionary timescales (Gavrilets \& Vose, [6]). In animals, there is increasing evidence of recent species diversification via ecological adaptation (e.g., Verheyen et al. [28]; Aguirre et al. [29]; Peccoud et al. [30]), but there is little evidence of this in plant species. Our study presents a potential case of rapid speciation in plants arising through adaptation to different abiotic environments.

The two riparian species showed different levels of genetic divergence from their non-riparian sister species. A. linearis and A. apiculata, which coexist on Yakushima Island, comprised distinct genetic clusters in the phylogenetic analysis, suggesting that they have accumulated genetic differentiation since their split. By contrast, the riparian species $A$. oblonga and its sister species $A$. macroclinidioides, which coexist on Okinawa, had no fixed 
Table 3 Tests of significance of migration and population size differences

\begin{tabular}{|c|c|c|c|c|c|c|c|c|c|c|c|c|}
\hline \multirow[b]{3}{*}{ Model } & \multicolumn{4}{|c|}{ A. linearis (1) - } & \multicolumn{4}{|c|}{ A. oblonga (1) - } & \multicolumn{4}{|c|}{ North (1) - South (2) } \\
\hline & \multicolumn{4}{|c|}{ A. apiculata (2) } & \multicolumn{4}{|c|}{ A. macroclinidioides (north) (2) } & \multirow[b]{2}{*}{$\log (P)$} & \multirow[b]{2}{*}{ df } & \multirow[b]{2}{*}{ 2LLR } & \multirow[b]{2}{*}{$P$} \\
\hline & $\log (P)$ & df & 2LLR & $P$ & $\log (P)$ & df & 2LLR & $P$ & & & & \\
\hline$\theta_{\mathrm{A}} \theta_{1} \theta_{2} m_{1}=m_{2}$ & 2.4387 & 1 & 6.4799 & 0.011 & -3.7251 & 1 & 8.0867 & 0.004 & 4.9933 & 1 & 2.6006 & 0.107 \\
\hline$\theta_{\mathrm{A}} \theta_{1} \theta_{2} m_{1} m_{2}=0$ & 5.6746 & 1 & 0.008 & 0.929 & -2.4051 & 1 & 5.4467 & 0.020 & 2.1984 & 1 & 7.7043 & 0.006 \\
\hline$\theta_{\mathrm{A}} \theta_{1} \theta_{2} m_{1}=0 m_{2}$ & 2.4387 & 1 & 6.4799 & 0.011 & -1.9985 & 1 & 4.6336 & 0.031 & 5.7494 & 1 & 0.0043 & 0.948 \\
\hline$\theta_{\mathrm{A}} \theta_{1} \theta_{2} m_{1}=0 m_{2}=0$ & 2.4394 & 2 & 6.4784 & 0.039 & -3.3128 & 2 & 7.2621 & 0.026 & 2.1981 & 2 & 7.7057 & 0.021 \\
\hline$\theta_{\mathrm{A}} \theta_{1}=\theta_{2} m_{1} m_{2}$ & 1.4532 & 1 & 8.4509 & 0.004 & -2.6265 & 1 & 5.8896 & 0.015 & 5.5204 & 1 & 1.3799 & 0.240 \\
\hline$\theta_{\mathrm{A}}=\theta_{1}=\theta_{2} m_{1} m_{2}$ & 0.2299 & 2 & 10.8975 & 0.004 & -6.3303 & 2 & 13.2971 & 0.001 & 4.156 & 2 & 1.4858 & 0.476 \\
\hline$\theta_{\mathrm{A}} \theta_{1}=\theta_{2} m_{1}=m_{2}$ & 1.4449 & 2 & 8.4674 & 0.014 & -10.614 & 2 & 21.8637 & 0.000 & 4.7742 & 2 & 4.5953 & 0.100 \\
\hline$\theta_{\mathrm{A}} \theta_{1}=\theta_{2} m_{1}=0 m_{2}=0$ & -5.1614 & 3 & 21.68 & 0.000 & -145.77 & 3 & 292.18 & 0.000 & 0.9275 & 3 & 10.8436 & 0.013 \\
\hline$\theta_{\mathrm{A}}=\theta_{1}=\theta_{2} m_{1}=m_{2}$ & 0.178 & 3 & 11.0012 & 0.012 & -10.805 & 3 & 22.2464 & 0.000 & 3.3505 & 3 & 4.8739 & 0.181 \\
\hline$\theta_{\mathrm{A}}=\theta_{1}=\theta_{2} m_{1}=0 m_{2}=0$ & -34.912 & 4 & 81.1808 & 0.000 & -279.85 & 4 & 560.328 & 0.000 & -1.3107 & 4 & 18.0984 & 0.001 \\
\hline$\theta_{\mathrm{A}}=\theta_{1} \theta_{2} m_{1} m_{2}$ & 1.6998 & 1 & 7.9577 & 0.005 & -3.4594 & 1 & 7.5554 & 0.006 & 4.8486 & 1 & 0.3983 & 0.528 \\
\hline$\theta_{\mathrm{A}}=\theta_{1} \quad \theta_{2} \quad m_{1}=m_{2}$ & 0.7965 & 2 & 9.7642 & 0.008 & -4.5652 & 2 & 9.7669 & 0.008 & 4.0603 & 2 & 2.9642 & 0.227 \\
\hline$\theta_{\mathrm{A}}=\theta_{1} \theta_{2} m_{1}=0 m_{2}=0$ & -34.889 & 3 & 81.1346 & 0.000 & -270.87 & 3 & 542.386 & 0.000 & -1.0241 & 3 & 12.4439 & 0.006 \\
\hline$\theta_{1} \theta_{A}=\theta_{2} m_{1} m_{2}$ & 1.5984 & 1 & 8.1604 & 0.004 & -3.9078 & 1 & 8.4522 & 0.004 & 4.6988 & 1 & 0.536 & 0.464 \\
\hline$\theta_{1} \theta_{\mathrm{A}}=\theta_{2} m_{1}=m_{2}$ & 0.4587 & 2 & 10.4398 & 0.005 & -4.8235 & 2 & 10.2835 & 0.006 & 4.0149 & 2 & 3.1385 & 0.208 \\
\hline$\theta_{1} \theta_{A}=\theta_{2} m_{1}=0 m_{2}=0$ & -25.328 & 3 & 62.0126 & 0.000 & -11.575 & 3 & 23.7873 & 0.000 & 1.1371 & 3 & 8.6762 & 0.034 \\
\hline
\end{tabular}

nucleotide differences, and they were not clustered separately. A previous study demonstrated the origin of the flood-resistant riparian species Solenogyne mikadoi, an endemic species in the Ryukyu Islands (Nakamura et al. [31]). It showed that the divergence between Solenogyne mikadoi and the other Solenogyne species with disjunct distributions in southeastern Australia dated back several million years. This indicates that the riparian Solenogyne mikadoi is a relict species that had diverged from its nonriparian relatives in ancient times, following geographical isolation through range shifts and local extinction. On Okinawa Island the two riparian species, A. oblonga and $S$. mikadoi, occur in flooded riversides. Our results indicate that the existing taxa of flood-resistant plants have various evolutionary histories.

\section{Evidence of historical gene flow between riparian/ non-riparian species}

Our IM simulations rejected the strict isolation model of population divergence and provided evidence of historical gene flow between riparian and non-riparian species. Recent coalescent-based analyses-such as the IM model-have been used to distinguish between the effects of shared ancestral polymorphism and gene flow on the level of genetic differentiation (Hey, [32]). The likelihood ratio test indicated unidirectional gene flow from non-riparian $A$. apiculata to riparian A. linearis.
One possible explanation of the unidirectional gene flow from riparian to non-riparian species is that the genes of riparian species are more difficult to move to nonriparian species inhabiting forest floor habitats. The nucleotide diversity of the riparian species was low, suggesting that their genomic components have undergone selection for specific types that have greater fitness in riparian habitats, but lower fitness in forest floor habitats. Although the statistical test suggested the existence of gene flow, the population migration rates $(2 \mathrm{Nm})$ between $A$. linearis and A. apiculata were below 1.0 for both directions, suggesting that the riparian/nonriparian species have been isolated genetically and are well-differentiated (Wright [33]).

By contrast, another set of riparian/non-riparian species, A. oblonga and A. macroclinidioides, was estimated to have exchanged genes at a relatively high rate since their divergence. The population migration rate from riparian A. oblonga to non-riparian A. macroclinidioides was 2.499 and that in the opposite direction was 0.526 , suggesting that there was sufficient gene flow to prevent genetic differentiation between the two species. In the STRUCTURE analysis, the genetic admixture and absence of population clustering in the two species also indicate relatively recent gene flow (Duchesne \& Turgeon, [25]). The greater amount of unidirectional gene flow from riparian $A$. oblonga to non-riparian $A$. 
macroclinidioides might be due to the difference in the strength of selective pressures compared to the other riparian/non-riparian pair: A. linearis and A. apiculata. Yakushima Island, where $A$. linearis and $A$. apiculata occur, is characterized by very high rainfall, up to 10,000 mm/year (Takahara \& Matsumoto, [34]), leading to the development of fast-flowing rivers that often cause flooding after rains. It thus seems likely that divergent selection arising from riparian/non-riparian habitats is relatively stronger on Yakushima Island than Okinawa Island. The riparian/non-riparian species in each system can hybridize each other and they are reproductively isolated mainly by ecological divergence (Mitsui et al. [17]). The contrasting patterns of gene flow between the two riparian/non-riparian species pairs may be attributed to the different evolutionary history of divergence, reflecting different level of adaptive divergence in each system.

The gene flow between the northern and southern lineages of Ainsliaea was estimated to be nearly zero $\left(\mathrm{m}_{1}\right.$ and $\left.\mathrm{m}_{2}=0.000\right)$, indicating that these regionally subdivided populations have long been strictly isolated. The estimated date of their divergence, $c a .0 .8$ mya, is congruent with the geological history that the Ryukyu-Taiwan island arc had separated from the nearby continent (Kimura, [35]). Notably, morphological differentiation cannot be recognized between these allopatric populations of A. macroclinidioides (Y. Mitsui, unpublished). Overall, the contrasting patterns of divergence (i.e., recent divergence among morphologically and ecologically distinct species vs. ancient population divergence within a single species) highlight the relative importance of adaptation to new ecological habitats for phenotypic evolution and speciation in this group of taxa.

\section{Levels of genetic diversity and population sizes}

We found lower genetic diversity and significantly smaller effective population sizes in riparian populations compared to the non-riparian populations. Flood-resistant riparian plants of various angiosperm and pteridophyte taxa have diversified globally (van Steenis $[10,18]$ ). The ranges of most riparian species are confined to fairly small areas, while the closely related non-riparian species have broad ranges. Therefore, in many cases, locally endemic riparian species are expected to have arisen from inland ancestral populations by adapting to flooding habitats. According to this assumption, our finding of lower genetic diversity and significantly smaller populations in riparian species might be a consequence of genetic drift during the process of adaptation to flooded habitats. During the process of local adaptation, natural selection might cause population declines and increase the potential for local extinction (Reznick and Ghalambor [36]). Consequently, founder populations are susceptible to genetic drift at the time of founding. Indeed, the effective population size of $A$. oblonga, which is thought to have speciated quite recently, was the lowest of the four species studied. Presently, the riparian species $A$. linearis occurs only on Yakushima Island and forms abundant metapopulations in the river systems (Mitsui et al. [37]). A. oblonga is also thought to maintain sufficiently large populations to prevent bottleneck effects that reduce genetic diversity (Y. Mitsui, personal observation). Given that the plants in riparian flooded habitats suffer severe selective pressures, the invasion of flooded habitats is likely achieved by small numbers of founders, leading to reduced genetic diversity and effective population sizes through genetic drift. The IM model assumes the absence of a population structure in the ancestral population and the sudden split, thus the model can be viewed as a simple case of divergence. In general, the effective population sizes of the descendant populations are well estimated, but the estimates of $\mathrm{N}_{\mathrm{A}}$ are reported to be sensitive to model misspecification (Becquet \& Przeworski, [38]). Thus, further investigations using other models of divergence with larger DNA data sets are needed to address the detailed demography.

\section{Conclusions}

This study demonstrated the recent origin of floodresistant riparian plants, which are remarkable examples of plant ecological adaptation to abiotic environments. The population demographic analyses showed evidence of historical gene exchange between riparian/non-riparian species with parapatric distribution. The two independently evolved riparian species showed reduced genetic diversity and effective population sizes, implying that strong natural selection by flooding frequently reduced diversity of riparian populations. The small sizes of effective populations of riparian species could have promoted the fixation of adaptive trait divergence in highly disturbed flooded habitats. Our results presented a potential case of rapid population differentiation and speciation by ecological adaptation in plants, and adaptive divergence between riparian and non-riparian species has been achieved in the face of gene flow.

\section{Methods}

\section{Sample collections}

For the riparian species, six populations of $A$. linearis on Yakushima Island and four populations of $A$. oblonga on Okinawa Island were collected (Figure 2). Each population was located in a different river system on each island. Non-riparian species comprised 12 populations of A. apiculata from the Japanese archipelago, which included five populations from Yakushima Island and 10 populations of $A$. macroclinidioides from the Ryukyu Islands and Taiwan, which included four populations from Okinawa Island. In total, 70 individuals of the four 
species were sampled across the distribution range. The localities and geographical ranges of the samples are shown in Additional file 3: Table S3. Total DNA was extracted from fresh or silica gel-dried leaves using the CTAB method based on Doyle \& Doyle [39].

\section{PCR amplification and sequencing of nuclear loci}

We determined the sequences of 10 nuclear loci. Three regions, GA2ox1, GTF, CPPS1, were amplified using primers originally developed based on the sequences of Asteraceae and a related family, which were obtained from the Compositae Genome Project Database (CGPDB: http://www.cgpdb.ucdavis.edu/) and GenBank database. CHS region was amplified using primers developed by Alvarez et al. [40], previously reported as single-copy genes. Six regions, A25, A27, B12, D10, D13, D22, were amplified using primers developed by Chapman et al. [41], which were universally applicable to the Asteraceae family. Locus information and a list of the primers used in the subsequent analyses are shown in Table 4.

\section{Haplotype determination}

For those sequences that contained more than one heterozygous site, we determined haplotypes probabilistically using PHASE software in DnaSP ver. 5.0 (Rozas et al. [42]). Haplotypes inferred by PHASE with a probability of $>0.5$ were highly consistent with those obtained by cloning method (Harrigan et al. [43]). To ensure accuracy, we used the haplotypes with a probability of $>0.8$ in subsequent analyses. In total, $1.14 \%$ of sequences were unable to be phased with a probability of $>0.8$.

\section{Sequencing analysis}

For each species, we calculated the number of segregating sites $(S)$, average number of pairwise nucleotide differences per site ( $\pi$; Nei, [44]), and $\theta$ (Watterson, [45]) for each locus. We estimated the minimum number of recombination events $(R m)$ within the 10 loci using the four-gamete test (Hudson \& Kaplan, [46]). To evaluate the neutral evolution of each locus, Tajima's $D$ (Tajima, [23]) was estimated, and deviations from neutral expectations were evaluated by 10,000 coalescent simulations. In addition, $D^{*}$ and $F^{*}$ of (Fu \& $\mathrm{Li}$, [47]) were estimated for loci deviating from neutral expectations using coalescent simulations. These summary statistics were estimated using DnaSP ver. 5.0 (Rozas et al. [42]). In addition, the HKA test (Hudson et al. [48]) across loci was performed at the species level using the HKA program (http://lifesci.rutgers.edu/\$heylab/heylabsoftware. htm\#HKA). This test is based on a prediction that follows from the neutral theory of molecular evolution, which states that loci exhibiting high rates of divergence between species will also exhibit high levels of variation within species.

\section{Phylogenetic and population structure analyses}

Previous studies have indicated that the four species comprise monophyletic relationships in nuclear ribosomal and chloroplast DNA data (Mitsui et al. [21]). To estimate the phylogenetic relationships among the four species, we reconstructed a phylogenetic network using the NeighborNet method (Bryant \& Moulton, [49]) implemented in SPLITTREE4 (Huson \& Bryant, [50]) because relationships among populations may not conform to a treelike pattern due to shared ancestral polymorphisms and potential gene flow (Nordborg et al. [51]). Only this analysis was performed without phasing haplotypes, and heterozygous SNPs were coded according to IUPAC. We used the uncorrected- $P$ distance as the metric, and ambiguous states were ignored in the analysis.

In addition, a Bayesian clustering analysis using STRUCTURE ver. 3.1 (Pritchard et al. [52]) was conducted to estimate the geographical structuring within species after determining the haplotypes for all samples. An admixture model was used, and the independence of allele frequencies among populations was assumed. The probability of assigning individuals into clusters was estimated using $5.0 \times 10^{5}$ iterations, following $3.0 \times 10^{5}$ iterations as the burn-in period. The number of clusters $(K)$ was set from 1 to 20 , and all runs were replicated 20 times to test the stability of the results. The most likely number of clusters was estimated according to the model value $(\Delta K)$ based on the second-order rate of change with respect to $K$ of the likelihood function following the procedure described by Evanno et al. [24].

\section{Estimating population demographic parameters and fitting models of divergence}

To estimate the population demographic history in the divergence of riparian and inland species, we employed the IM model (Nielsen \& Wakeley, [53]; Hey \& Nielsen, [8]) using the program IMa (Hey \& Nielsen, [54]). The IM model uses a Markov chain Monte Carlo (MCMC) method to estimate the posterior probability densities of six demographic parameters: the divergence time $(t)$, bidirectional migration rates $\left(m_{1}\right.$ and $\left.m_{2}\right)$, and the effective population sizes of the ancestral $\left(\theta_{\mathrm{A}}\right)$ and descendent populations $\left(\theta_{1}\right.$ and $\left.\theta_{2}\right)$. After several preliminary runs to optimize prior boundaries for the six parameters, we conducted runs for $3-5 \times 10^{6} \mathrm{MCMC}$ steps following a 300,000 burn-in period from which genealogies were saved every 100 steps. To ensure proper mixing, the run was performed using 20 independent chains and 10 swap attempts per step under Metropolis coupled with a geometric heating scheme of parameters $g 1=0.05$ and $g 2=0.1$. To check the convergence, plotted trend lines and the effective sample size (ESS) values were examined for each run. In addition, three independent runs for 
Table 4 Locus information and list of the primers used in this study

\begin{tabular}{|c|c|c|c|c|c|c|c|}
\hline Locus & Best BLAST hit & E-value & Species & Gene & Primer name & Sequences 5'-3' & Primer source \\
\hline \multirow[t]{2}{*}{ GA20x1 } & AB031206 & $1.00 \mathrm{E}-104$ & Lactuca sativa & gibberellin 2-oxidase 1 & GA2Ox1 Ai2 F & GACCAAGCGTGATTTACTCTG & Developed for this study \\
\hline & & & & & GA2Ox1 R & TTCTCGCTCAATGGTGGTCCT & Developed for this study \\
\hline \multirow[t]{2}{*}{$\mathrm{CHS}$} & X91343 & $8.00 \mathrm{E}-11$ & Leibnitzia anandria & chalcone synthase & $1266 \mathrm{~F}$ & ATCACCCACCTCATCTTCTGCAC & Álvarez et al. [40] \\
\hline & & & & & $1990 \mathrm{R}$ & TCCAAAAGATCGAGTTCCAGTC & Álvarez et al. [40] \\
\hline \multirow[t]{2}{*}{ GTF } & AB070746 & $5.00 \mathrm{E}-06$ & Vigna angularis & glucosyltransferase-3 & GTF F & ACCAGATGCACCCTATTCATCT & Developed for this study \\
\hline & & & & & GTF R & AAAGCGTGGTGGTGCTGATT & Developed for this study \\
\hline \multirow[t]{2}{*}{ CPPS1 } & AF034545 & $1.00 E-32$ & Stevia rebaudiana & copalyl pyrophosphate synthase (Cpps1) & CPPS1 F & GAKGGAGAGATAACTGTATC & Developed for this study \\
\hline & & & & & CPPS1 R & GGKTYCGTCTTGCATAGATT & Developed for this study \\
\hline \multirow[t]{2}{*}{ A25 } & EF519751 & 1.00E-18 & Carthamus oxyacanthus & Unknown & A25 F & TTGCATGSTCTTATCAGTCC & Chapman et al. [41] \\
\hline & & & & & $A 25 R$ & GAAGABCCCATCCARCAGAAGAG & Chapman et al. [41] \\
\hline \multirow[t]{2}{*}{ A27 } & EF519770 & 4.00E-11 & Carthamus oxyacanthus & Unknown & $\mathrm{A} 27 \mathrm{~F}$ & CTTGCAWTGAATGTCATGTGGAAG & Chapman et al. [41] \\
\hline & & & & & $A 27 R$ & GCTCCCCARCATTTCA & Chapman et al. [41] \\
\hline \multirow[t]{2}{*}{ B12 } & EF519836 & $3.00 \mathrm{E}-68$ & Carthamus lanatus & Unknown & $\mathrm{B} 12 \mathrm{~F}$ & CAAGTGGCTGCAGCCATGGG & Chapman et al. [41] \\
\hline & & & & & $\mathrm{B} 12 \mathrm{R}$ & ACATCRGGMACCATTCCWCCGGTGT & Chapman et al. [41] \\
\hline \multirow[t]{2}{*}{ D10 } & HM640003 & $5.00 \mathrm{E}-15$ & Medicago truncatula & somatic embryogenesis receptor kinase 5 (SERK5) & D10 F & GATTGCTYGTTTATCCCTACATGG & Chapman et al. [41] \\
\hline & & & & & D10 R & ATATTTGCAGCTTTCACATC & Chapman et al. [41] \\
\hline \multirow[t]{2}{*}{ D13 } & No hit & - & - & Unknown & D13 F & ATGTCAGGTTTTGGRCAYCGTGT & Chapman et al. [41] \\
\hline & & & & & D13 R & CCAGARTAGAAATCAACATTYGGGTAC & Chapman et al. [41] \\
\hline \multirow[t]{2}{*}{ D22 } & EF484030 & 5.00E-19 & Carthamus tinctorius & Unknown & $\mathrm{D} 22 \mathrm{~F}$ & CGHAGAACTCCAGCTGAA & Chapman et al. [41] \\
\hline & & & & & D22 R & GCTTCTTCTTGCCTGATGCT & Chapman et al. [41] \\
\hline
\end{tabular}


each data set were examined for consistency. An infinite site model of mutation was applied to all loci. The analyses were performed using the largest non-recombining block for each locus (see Table 1).

After all runs were converged under the full model, which estimates the six demographic parameters, we tested the fit of the data to simpler demographic models using the nested model approach in the L-Mode option of IMa. This test evaluates the presence or absence of gene flow between descendent populations and the population size differences among present and ancestral populations (Hey \& Nielsen, [54]). We compared loglikelihoods of full and nested models in which one or both directions of gene flow were absent and present and ancestral populations were equal sizes.

Demographic parameters were scaled to the neutral mutation rate $(\mu)$. Mutation rates of nuclear genes for the studied samples were unknown. Thus, we calibrated the mutation rates of the GA2ox1 and CHS genes by comparing the sequences of perennial species in various taxa of Asteraceae because the studied species are perennials, although they can bloom and produce seeds within the year of germination (M. Mitsui, pers. obs.). A previous phylogenetic study by Kim et al. [55] estimated the splitting time among major Asteraceae clades and suggested that the tribes Cardueae and Mutisieae, as well as LALV (Lactuceae, Arctoteae, Liabeae, and Vernonieae) and Astroid, diverged c. 33-38 million years ago (mya). We calculated the average nucleotide divergence $(K)$ in the sequences between the tribes Cardueae and Mutisieae and tribes LALV and Astroid using species from various taxonomic groups. The mutation rate per site per year $(\mu)$ was then calculated by $\mu=K / 2 T$, in which $T=35.4$ mya was used for each of the GA2ox1 and CHS regions. The geometric mean of the mutation rates for GA2ox $(6.79 \times$ $10^{-9}$ substitutions/site/year) and CHS $\left(8.26 \times 10^{-9}\right.$ substitutions/site/year) was estimated to be $7.49 \times 10^{-9}$ substitutions/site/year, and this value was used to rescale the IMa parameter estimates.

\section{Additional files}

Additional file 1: Table S1. Haplotype compositions. The numbers represent the haplotypes of individuals at each locus.

Additional file 2: Table S2. Results of neutrality tests for each of the 10 loci and each species. For Ainsliaea macroclinidioides, the southern populations were excluded in the analyses.

Additional file 3: Table S3. Sampling localities. Sampling sites are shown in Figure 2.

\section{Competing interests}

The authors declare that they have no competing interests.

\section{Authors' contributions}

YM designed the study, collected and assembled plant samples, carried out the molecular analyses and drafted the manuscript. HS participated in the overall design of the study, collected some of the samples, and contributed to drafting the manuscript. Both authors have read and approved the final manuscript.

\section{Acknowledgement}

We thank Dr. Ching-I. Peng and Mr. Chien-I. Huang (Research Center for Biodiversity, Academia Sinica, Taipei), Dr. Yun-Fei Deng (Herbarium South China Botanical Garden, Guangdong), Dr. Tomoko Fukuda (National Museum of Science and Nature, Tokyo), and Ms. Kanako Sugahara (Kyoto University, Japan) for assisting with plant collections in the field. We are grateful to Dr. Hajime Ikeda (National Museum of Science and Nature, Tokyo) for valuable comments on data analyses. This study was supported by a Grant-in-Aid for Scientific Research (\#21370036) and JSPS Fellows from the Ministry of Education, Culture, Science, Sports and Technology, Japan.

\section{Author details}

'Faculty of Agriculture, Tokyo University of Agriculture, Funako 1737, Atsugi, Kanagawa 243-0034, Japan. ${ }^{2}$ Graduate School of Human and Environmental Studies, Kyoto University, Yoshida Nihonmatsu-cho, Sakyo-ku, Kyoto 606-8501, Japan.

Received: 3 September 2012 Accepted: 19 December 2012 Published: 28 December 2012

\section{References}

1. Schluter D: The Ecology of Adaptive Radiation. New York: Oxford University Press; 2000.

2. Schluter D: Evidence for ecological speciation and its alternative. Science 2009, 323:737-741.

3. Coyne JA, Orr HA: Speciation. Sunderland, MA: Sinauer Associates; 2004

4. Rundle HD, Nosil P: Ecological speciation. Ecol Lett 2005, 8:336-352.

5. Sobel JM, Chen GF, Watt LR, Schemske DW: The biology of speciation. Evolution 2010, 62:295-315.

6. Gavrilets S, Vose A: Dynamic patterns of adaptive radiation. Proc Natl Acad Sci USA 2005, 102:18040-18045

7. Hendry AP, Nosil P, Rieseberg LH: The speed of ecological speciation. Funct Ecol 2007, 21:455-464.

8. Hey J, Nielsen R: Multilocus methods for estimating population sizes, migration rates and divergence time, with applications to the divergence of Drosophila pseudoobscura and D. persimilis. Genetics 2004, 167:747-760.

9. Hey J: The divergence of chimpanzee species and subspecies as revealed in multipopulation isolation-with-migration analysis. Mol Biol Evol 2010, 27:921-933.

10. van Steenis CGGJ: Rheophytes of the World. Netherlands: Sijithoff \& Noordhoff; 1981

11. Usukura M, Imaichi R, Kato M: Leaf morphology of a facultative rheophyte, Farfugium japonicum var. luchuense (Compositae). J Plant Res 1994, 107:263-267.

12. Imaichi R, Kato M: Speciation and morphological evolution in rheophytes. In Evolution and Diversification of Land Plants. Edited by Iwatsuki K, Raven PH. Tokyo: Springer; 1997:309-318.

13. Kato M: Evolutionary Morphology of plants. Tokyo: University of Tokyo Press; 1999 (in Japanese).

14. Tsukaya H: Leaf anatomy of rheophyte, Dendranthema yoshinaganthum (Asteraceae), and of hybrids between $D$. yoshinaganthum and a closely related non-rheophyte, D. indicum. J Plant Res 2002, 115:329-333.

15. Setoguchi H, Kajimaru G: Leaf morphology of the rheophyte, Rhododendron indicum f. otakumi (Ericaceae). Acta Phytotax Geobot 2004 55:45-54.

16. Nomura N, Setoguchi H, Takaso T: Functional consequences of stenophylly for leaf productivity: comparison of the anatomy and physiology of a rheophyte, Farfugium japonicum var. luchuence, and a related non-rheophyte, F. japonicum (Asteraceae). J Plant Res 2006, 119:645-656.

17. Mitsui $Y$, Nomura N, Isagi Y, Tobe H, Setoguchi H: Ecological barriers to gene flow between riparian and forest species of Ainsliaea (Asteraceae). Evolution 2011, 65:335-349.

18. van Steenis CGGJ: Rheophytes of the world: supplement. Allertonia 1987 4:267-330. 
19. Mitsui $Y$, Setoguchi $H$ : Recent origin and adaptive diversification of Ainsliaea (Asteraceae) in the Ryukyu Islands: molecular phylogenetic inference using nuclear microsatellite markers. Plant Syst Evol 2012, 298:985-996.

20. Watanabe K, Yahara T, Kadota H: Natural hybrid populations between chasmogamous and cleistogamous species, Ainsliaea faurieana and A. apiculata (Asteraceae; Mutisiae): morphology, cytology, reproductive mode and allozyme variation. Plant Spec Biol 1992, 7:49-59.

21. Mitsui Y, Chen ST, Zhou ZK, Peng Cl, Deng YF, Setoguchi H: Phylogeny and biogeography of the genus Ainsliaea (Asteraceae) in the Sino-Japanese Region based on nuclear rDNA and plastid DNA sequence data. Ann Bot 2008, 101:111-124.

22. Koyama H: Ainsliaea DC. In Flora of Japan. Volume IIlb. Edited by Iwatsuki K, Yamazaki T, Boufford DE, Ohba H. Tokyo: Kodansha; 1995:207-209.

23. Tajima F: Statistical method for testing the neutral mutation hypothesis by DNA polymorphism. Genetics 1989, 123:585-595.

24. Evanno GS, Regnaut S, Goudet J: Detecting the number of clusters of individuals using the software structure: a simulation study. $\mathrm{Mol}$ Ecol 2005, 14:2611-2620.

25. Duchesne $P$, Turgeon J: FLOCK: A method for quick mapping of admixture without source samples. Mol Ecol Res 2009, 9:1333-1344.

26. Hey J, Won YJ, Sivasundar A, Nielsen R, Markert JA: Using nuclear haplotypes with microsatellites to study gene flow between recently separated Cichlid species. Mol Ecol 2004, 13:909-919.

27. Ikeda $H_{1}$ Fujii $N$, Setoguchi $H$ : Application of the Isolation with Migration model demonstrates the Pleistocene origin of geographic differentiation in Cardamine nipponica (Brassicaceae), an endemic Japanese alpine plant. Mol Biol Evol 2009, 26:2207-2216.

28. Verheyen E, Salzburger W, Snoeks J, Meyer A: Origin of the superflock of cichlid fishes from Lake Victoria, East Africa. Science 2003, 300:325-329.

29. Aguirre WE, Ellis KE, Kusenda M, Bell MA: Phenotypic variation and sexual dimorphism in anadromous threespine stickleback: implications for postglacial adaptive radiation. Biol J Linn Soc 2008, 95:465-478

30. Peccoud J, Simon J-C, McLaughlin HJ, Moran NA: Post-Pleistocene radiation of the pea aphid complex revealed by rapidly evolving endosymbionts. Proc Natl Acad Sci USA 2009, 106:16315-16320.

31. Nakamura K, Denda T, Kokubugata G, Forster PI, Wilson G, Pen C-I, Yokota M: Molecular phylogeny reveals an antitropical distribution and local diversification of Solenogyne (Asteraceae) in the Ryukyu Archipelago of Japan and Australia. Biol J Linn Soc 2012, 105:197-217.

32. Hey J: Recent advances in assessing gene flow between diverging populations and species. Curr Opin Genet Dev 2006, 16:592-596.

33. Wright SJ: Evolution in mendelian populations. Genetics 1931, 16:97-159.

34. Takahara $H$, Matsumoto J: Climatological study of precipitation distribution in Yaku-shima Island, southern Japan. J Geog 2002, 111:726-746.

35. Kimura M: Quaternary paleogeography of the Ryukyu arc. J Geog 1996 105:259-285.

36. Reznick DN, Ghalambor CK: The population ecology of contemporary adaptations: what empirical studies reveal about the conditions that promote adaptive evolution. Genetica 2001, 112-113:183-198.

37. Mitsui $Y$, Isagi $Y$, Setoguchi $H$ : Multiple spatial scale patterns of genetic diversity in riparian populations of Ainsliaea faurieana (Asteraceae) on Yakushima Island, Japan. Am J Bot 2010, 97:101-110.

38. Becquet C, Przeworski M: Learning about modes of speciation by computational approaches. Evolution 2009, 63:2547-2562.

39. Doyle JJ, Doyle JL: A rapid DNA isolation procedure for small quantities of fresh leaf tissue. Phytochem. Bull Bot Soc Am 1987, 19:11-15.

40. Álvarez I, Costa A, Feliner GN: Selecting single-copy nuclear genes for plant phylogenetics: a preliminary analysis for the Senecioneae (Asteraceae). J Mol Evol 2008, 66:276-291.

41. Chapman MA, Cheng JC, Weisman D, Kesseli RV, Burke JM: Universal markers for comparative mapping and phylogenetic analysis in the Asteraceae (Compositae). Theor Appl Genet 2007, 115:747-755.

42. Rozas J, Sanchez-DelBarrio JC, Messeguer X, Rozas R: DnaSP, DNA polymorphism analyses by the coalescent and other methods. Bioinformatics 2003, 19:2496-2497.

43. Harrigan RJ, Mazza ME, Sorenson MD: Computation vs. cloning: evaluation of two methods for haplotype determination. Mol Ecol Res 2008, 8:1239-1248.
44. Nei M: Molecular Evolutionary Genetics. New York: Columbia University Press; 1987.

45. Watterson GA: On the number of segregating sites in genetical medels without recombination. Theor Popul Biol 1975, 7:256-276.

46. Hudson RR, Kaplan NL: Statistical properties of the number of recombination events in the history of a sample of DNA sequences. Genetics 1985, 111:147-164.

47. Fu YX, Li WH: Statistical tests of neutrality of mutations. Genetics 1993, 133:693-709.

48. Hudson RR, Kreitman M, Aguade M: A test of neutral molecular evolution based on nucleotide data. Genetics 1987, 116:153-159.

49. Bryant D, Moulton V: Neighbor-net: an agglomerative method for the construction of phylogenetic networks. Mol Biol Evol 2004, 21:255-265.

50. Huson DH, Bryant D: Application of phylogenetic networks in evolutionary studies. Mol Biol Evol 2006, 23:254-267.

51. Nordborg M, Hu TT, Ishino Y, et al: The pattern of polymorphism in Arabidopsis thaliana. PLOS Biol 2005, 3:e196.

52. Pritchard JK, Stephens M, Donnelly P: Inference of population structure using multilocus genotype data. Genetics 2000, 155:945-959.

53. Nielsen R, Wakeley J: Distinguishing migration from isolation: a Markov chain Monte Carlo approach. Genetics 2001, 158:885-896.

54. Hey J, Nielsen R: Integration within the Felsenstein equation for improved Markov chain Monte Carlo methods in population genetics. Proc Natl Acad Sci USA 2007, 104:2785-2790.

55. Kim KJ, Choi KS, Jansen RK: Two chloroplast DNA inversions originated simultaneously during the early evolution of the Sunflower family (Asteraceae). Mol Biol Evol 2005, 22:1783-1792.

doi:10.1186/1471-2148-12-254

Cite this article as: Mitsui and Setoguchi: Demographic histories of adaptively diverged riparian and non-riparian species of Ainsliaea (Asteraceae) inferred from coalescent analyses using multiple nuclear loci. BMC Evolutionary Biology 2012 12:254

\section{Submit your next manuscript to BioMed Central and take full advantage of:}

- Convenient online submission

- Thorough peer review

- No space constraints or color figure charges

- Immediate publication on acceptance

- Inclusion in PubMed, CAS, Scopus and Google Scholar

- Research which is freely available for redistribution
C) BioMed Central 